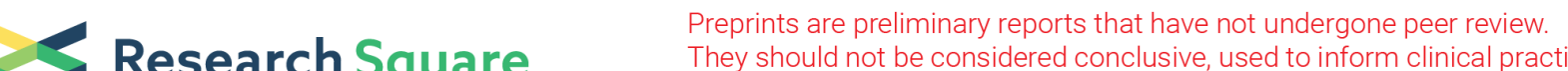 Research Square They should not be considered conclusive, used to inform clinical practice, or referenced by the media as validated information.
}

\section{Reducing Maternal Mortality: an Assessment of the Availability and Quality of Emergency Obstetric and Newborn Care in Esan Central Local Government Area of Edo State}

Sunday Emmanuel JOMBO ( $\nabla$ jombosunday@yahoo.com )

ISTH, IRRUA https://orcid.org/0000-0001-6313-7598

\section{Ehigha ENABUDOSO}

University of Benin Teaching Hospital

Anthonia NJOKU

ISTH,IRRUA

Jedidiah AFEKHOBE

ISTH,IRRUA

\section{Research article}

Keywords: Maternal mortality; Emergency Obstetric and newborn Care; Esan central; AMDD Handbook

Posted Date: September 8th, 2019

DOl: https://doi.org/10.21203/rs.2.14094/v1

License: (c) (i) This work is licensed under a Creative Commons Attribution 4.0 International License.

Read Full License 


\section{Abstract}

\section{Background}

There is global public health burden of maternal mortality and is worse in Sub-Saharan Africa. Esan Central LGA in Nigeria has an estimated maternal mortality of 1747 per 100,000 live births which is unacceptably high. Emergency obstetric care has been advocated as a measure to avert maternal mortality as about $15 \%$ of pregnancies developed complications which may be unpredictable. There is therefore need to access the availability and quality of EmOC in the area. This study aimed to assess the availability and quality of emergency obstetric and newborn care (EmONC) services in the area

Methods

We conducted a descriptive cross-sectional study and an in-depth interview. Data was collected using UN/AMDD assessment tools (Handbook). Forty key informants' interviews with major facility managers, pregnant women and health care providers were also done and triangulated. Analysis was done using IBM SPSS statistics- 20, while the in-depth interviews were audio taped, transcribed and analyzed by thematic coding. In addition EmONC services indicators were calculated.

Result

The availability of EmONC services in Esan central LGA was 3.7/500,000 population. The availability of EmONC services was limited at the primary and secondary level of health care. The comprehensive EmOC was adequate (3.7/500000 population) and it is available at the tertiary health facility. The met need for EmONC was $62.6 \%$, obstetric case fatality was $1.2 \%$, and caesarean section rate was $24 \%$, while the still birth rate was $2.6 \%$. The respondents had adequate knowledge and concern about the burden of maternal death. Major causes of maternal death reported were haemorrhage, hypertension / convulsion in pregnancy and prolong labour. Major contributing factors to maternal death are lack of money, poor antenatal care, and poor attitudes of health care providers, inappropriate referral network, lack of equipment and EmONC drugs, inadequate skill birth attendants and delay in getting treatment. Overall remark on the quality of EmONC services was poor.

Conclusion

There are limited EmONC services at the primary and secondary health centers that require urgent attention in effort to reducing maternal mortality. There is need for supply of equipment, emergency obstetric care drugs, training and re-training of staff. The community and the health care providers need re-orientation as to the reproductive health care requirements of the people in such a manner that is client centered and with appropriate referral network.

\section{Background}


Maternal mortality is a global public health burden [1]. Globally in 2015, 303,000 maternal deaths occurred. Over ninety nine percent of these annual maternal deaths occur in low and middle income countries while $66 \%$ in particular occurred in Sub-Saharan Africa [1].About $75 \%$ of these maternal mortalities are caused by haemorrhage, sepsis, unsafe abortion, pre-eclampsia/ eclampsia, ruptured uterus, obstructed labour and its sequelae, and extra-uterine pregnancy [1-3]. Life threatening complications will occur in about $15 \%$ of pregnant women, they cannot be predicted accurately or prevented completely during pregnancy, delivery or immediate postpartum $[4,5]$. Although these complications are highly unpredictable and less preventable, they can be treated by prompt, available and quality emergency obstetric and newborn care (EmONC) services [3-8]. The National Demography and Health Survey (NDHS) data showed that Nigeria's Maternal Mortality Rate (MMR) is high and stands at 576 per 100,000 live births [9]. In Irrua Specialist Teaching Hospital (ISTH), Okunsanya and co showed that the maternal mortality rate was 1747 per 100,000 live births, of which in about $77.8 \%$ of cases they were associated with delays [12].

Although several efforts have been strategized to reducing maternal mortality, the three most indispensable requirements that are strongly evidence based are the access to available and quality EmONC services, family planning and care of a skill birth attendant during all deliveries $[2,4,5]$. It has been estimated that with the availability of EmOC services $60 \%$ of maternal mortality, $45 \%$ of neonatal deaths and $45-75 \%$ of still birth could be avoided[2,4]. Paxton et al, 2004 in a systematic review acknowledged the difficulty in measuring maternal mortality, which in turn limits assessment of the impact of EmOC services and also the ethical dilemma in doing a randomized study. Despite these limitations, they concluded that there is a strong reason to suggest that EmOC should be a key element in any policy for reducing maternal death [2]. Universal access to EmONC is considered essential to reducing maternal mortality and it should be available to all pregnant women and newborns (WHO, 2014). No wonder that provision of EmOC service is one of the components of the World Health Organization(WHO)'Making Pregnancy Safer' programme which is a newer term for safe-motherhood initiative aimed at reducing maternal mortality [9,13-16]. Rana et al (2007) in Nepal upgraded eight health facilities by providing infrastructure, equipments, training, data collection, policy advocacy and community information activities, found improved met need for EmOC from 1.9 to $16.9 \%$ and a reduction in obstetrics case fatality from 2.7 to $0.3 \%$ [13]. This showed the positive impact of EmONC effectiveness in reducing maternal mortality. Dumont et al (2013) in a cluster randomized controlled trial, after a base line survey of EmOC facilities, provided an intervention in the form of an interactive workshops and educational outreach on maternal death review and provision of quality EmOC services. He also found a marked reduction in maternal death in the intervention hospital than the control [17]. Holmar et al (2015) in a systematic review observed an inverse relationship between met need for EmOC and maternal mortality and correlate proportionally with available skilled birth attendant [20].

In Nigeria, the Federal Ministry of Health $(\mathrm{FMOH})$ conducted a national survey on essential obstetrics care and found that only $20 \%$ of health facilities studied performed the signal functions [22]. These are mainly tertiary health facilities with few of the secondary and primary health facility providing EmOC services [22]. This is not different from most developing countries. Babatunde et al (2012) in his facility based 
review of the status of EmOC in a LGA within South-South, Nigeria found that none of the facilities that should serve as B-EmOC facilities were able to do so and only one could perform C-EmOC services [5]. This is not different from a similar survey in Uganda by Wilunda et al, he found out that none of the facilities for B-EmOC services is qualified as such, with operative vaginal delivery and manual vacuum aspiration were the commonest missing functions [23]. The met need for EmOC was $9.9 \%$ while absolute obstetric case fatality was $3.0 \%$ which is higher than the UN recommendation $[18,19,23]$. Pearson et al, 2004 in a multinational EmOC survey by AMDD including Uganda found adequate C-EmOC services but lesser facility for B-EmOC services [24]. His findings also showed that between $0.6-8.8 \%$ of all deliveries occurs in EmOC facility while only $2.1-18.5 \%$ of all absolute obstetrics complications were treated, thus showing limited access to women in need of life- saving services[24]. Almost all the surveys on availability of EmOC at National and Sub- National levels showed gross inadequacy of B-EmOC services. In particular, they lack materials for evacuation of retained products of conception (MVA) $[22,25,26-30$, 32-51,54-57] Most surveys since 1997 have showed that in over 40 countries there are available comprehensive EmOC as recommended by UN / WHO; however there are inadequate or none availability of B-EmOC $[2,4,6]$.

In order to monitor the availability and quality of EmONC services, experts from the Mailman School of Public Health at Columbia University, with Support and adoption by the United Nation's Children Funds (UNICEF) and the World Health Organization (WHO) formed a guidline [18,19]. This guideline uses eight different care packages, referred to as 'signal functions', which were described as lifesaving to major causes of maternal death [18,19]these care packages includes; parenteral antibiotics, parenteral oxytocic, parenteral anticonvulsants, manual removal of placenta, removal of retained products, assisted vaginal delivery, provision of surgery (caesarean section) and safe blood transfusion services. The first six care packages constitute B-EmOC while the whole eight make up the comprehensive emergency Obstetric care (C-EmOC). Six EmONC indicators, as well as the type of data required calculating these indicators with the lowest and/or highest acceptable standards were also established. The guideline was reviewed and updated in 2009, now incorporating basic neonatal resuscitation to the B-EmOC and thus was renamed Emergency Obstetrics and Newborn Care (EmONC) [2, 3,11,16-19].

Quality EmOC services is technically difficult to define because of its complex nature; however it involves alertness that will enable a health center to respond appropriately and timely to women with obstetrics emergencies in a manner that fulfils the needs of the patient with almost technical competency[20,21].

Nigerian federal ministry of health in its plan of health for all ages proposes to use Primary Health Care Centres (PHC) as their centre of focus. The Nigeria health care system is built on the foundation of three tiers: primary, secondary and tertiary health care centers. The primary health care is under the control of the local government, the secondary health care under the state government, while the tertiary hospitals are under the federal government. It is expected that the $\mathrm{B}-\mathrm{EmOC}$ be available at the primary health care centers while the C-EmOC is expected in the secondary and tertiary health centres. Esan Central LGA is thus a privileged environment to have a federal teaching hospital, state general hospital and several registered primary health centers; however the maternal mortality is still very high [12]. 
The importance of EMOC need assessment cannot be over emphasized as it helps to identify gaps and problems through qualitative and quantitative data on the adequacy and quality of EMOC services $[18,19,49]$.It provide a critical steps in improving equitable access to EmOC services and help strengthens overall health systems $[18,19]$. These will help guide policy decisions, planning and budgeting to reform and strengthens the health system most especially with this era of global agenda of Sustainable Development Goals (SDG)-2030. This study therefore aimed to assess the availability and quality of emergency obstetric and newborn care in Esan Central LGA, Edo state.

\section{Research Questions.}

1. Reducing maternal death; are there adequate emergency obstetric care services in Esan central LGA?

2. Reducing maternal death, if there are adequate EmONC services: what are their qualities in Esan central LGA

\section{General Objective}

To assess the availability and quality of Emergency Obstetric and Newborn Care (EmONC) Services in Esan Central LGA of Edo State.

\section{Specific Objectives}

1. To determine the number of health center offering maternity services in proportion to the population of Esan Central LGA.

2. To determine the number of health centers with adequate facilities for EmONC services in proportion to the population of Esan Central LGA.

3. To determine the preparedness of health facilities to offer quality EmONC services in Esan Central LGA.

4. To determine the Perception on the quality of EmONC services in Esan Central LGA.

\section{Methods}

\section{STUDY LOCATION}

Esan central is one of the LGA in Edo State. By the National Population Commission of Nigeria census of 2006, Esan central LGA has a population of 105,242 with a population density of $476.09 \mathrm{~km}^{2}$. By 2011 projection of National Population Commission based on the assumption of same growth rate for all LGAs within a state, an estimate of 134,190 was recorded for Esan Central LGA with a projection to 2015. Nigeria has a crude birth rate of $38.9 / 1000$ birth (NDHS, 2013). Based on the figures from the Edo State ministry of health; Health facility data for 2015, Esan Central LGA has one tertiary hospital, two district (general) hospitals and 19 primary health centers (14 public and 5 private). 


\section{STUDY DESIGN}

A mixed research involving a descriptive cross-sectional study and an In-depth Interview was done. This involved the survey of all the health center providing maternity services in Esan central LGA of Edo state that are registered by the state ministry of health.

\section{DATA COLLECTION}

Health facility assessment was done using the UN/ WHO/ UNICEF handbook for monitoring EmONC. Data collection was done in conjunction with my research assistants who were trained on the principles of the research. All health care centres offering maternity services and registered with the state ministry of health were assessed. Eligible health facilities were visited and interviews were conducted with the person(s) in charge of the maternity Unit or health centre. Record from the labour ward, antenatal ward, postnatal ward and gynaecology ward were reviewed. Data on performance of EmOC signal functions, number of deliveries, identified obstetric complications, maternal deaths and stillbirths were collected over a period of six months prior to the interviews (October, 2017- March, 2018). Direct observation using a UN EmONC checklist was used to assess for the availability of supplies and equipments for performing EmONC services. Based on the UN guidelines, the EmOC process indicators were determined.

To gain more insight into the study a qualitative study was done through an in-depth interview (IDI) of the pregnant antenatal women, health care providers (nurse, midwife, doctors in the five of the facilities. Respondents were randomly selected among the antenatal attendee. Eight interviews were done in each of the five centers, thus a total of forty interviews were done. This consists of doctors, nurse, midwife and antenatal women. Each of the interviews consists of questions on EmONC services in the area as regards reduction of maternal mortality. The interviews were audio-taped, transcribed, coded and analyzed using thematic coding. The result helps to gain insights into the nature of the burden of maternal death, common causes, where to seek care in cases of emergency complications and what can be done to reducing maternal death. It also show-cases participant's perception of the quality of EmONC services in the area.

\section{DATA ANALYSIS}

The quantitative data was collected and entered into IBM SPSS Statistic- 20 for analysis using descriptive analysis with percentages and proportions calculated. While the qualitative data were audiotaped, transcribed and analyze using thematic approach.

\section{ETHICAL CONSIDERATION}

Ethical approval was obtained from the ethical committee of Irrua Specialist Teaching Hospital, Irrua (ISTH / HREC / 20171219/47). We also obtain permission from the Esan Central Local Government Council. Written Informed consent was obtained from the participants before enlistment into the study. 


\section{Results}

A total of 22 health facilities offering maternity services were visited out of which two that are private owned were not functional, hence 20 centers were assessed and analyzed. These include seventeen primary health care centers (85\%), two secondary health centers $(10 \%)$ and one tertiary health centre $(5 \%)$. Seventeen also were public health care centre while three were private health centre as showed in table 1. The secondary and the tertiary health care centre are designed to offer comprehensive EmONC while the primary health care centres are designed to offer basic EmONC services.

Physically these facilities exceeded the standard UN/WHO recommendation of four basic and at least one comprehensive EmONC services for a population of 500000, however there are limited availability of EmONC signal functions. Esan central LGA has a population of 134,190 according to the 2011 population projection by National population commission (NPC) assuming a universal growth rate. The national crude birth rate is $38.9 / 1000$ birth (NDHS 2013).

Only one of the health facilities could offer all the 9 -EmONC signal functions and it is designated as a comprehensive EmONC service centre. The primary and the secondary health centers have limited EmONC signal functions as none could offer all the 7 versus 9 signal functions respectively as showed in table 2 and figure 1. Using the AMDD hand book (which assumes all or none package for EmONC services) there is only one health facility with complete EmONC services. The number of EmONC facility in proportion to the population is (number of B-EmONC + C-EmONC/population of the area $X 500,000$ ) $=$ $1 / 134190 \times 500000=3.7 / 500000$ population. Thus the availability of EmONC in the area is $3.7 / 500000$ population. This is less than the UN recommendation of 5/ 500000 population. Similarly the availability of comprehensive EmONC is 3.7/500000 population. This is higher than the UN recommendation of $1 / 500000$ population. All the facilities had parenteral antibiotics and oxytocic as shown in figure 1. Magnesium Sulphate was not available in any of the primary and secondary health facilities. One midwife when interviewed on how she manage cases of high blood pressure said she gives antihypertensive drugs and if patient fails to response she will refer, another said she will just refer. The main reason for none performance of EmONC signal function is lack of supply of necessary drugs, equipments and inadequate skilled personnel. All the EmOC indicators did not met the minimum or maximum standard according to the UN/WHO recommendation except for the comprehensive EmOC as shown in table 3. The met need for EmOC is $62.6 \%$ as against $100 \%$ while the obstetric case fatality is $1.2 \%$ which is more than the less than $1 \%$ recommended by the UN.

The primary health care centers have available nurses and midwives but no functional 24 hour coverage. Similarly the secondary has nurses and midwife with one doctor that is available on call basis. It is only at the tertiary health care facility that there are nurses, midwife, doctor and obstetrician available on a 24 hour functional duty roster.Maternal death were recorded at the tertiary hospital and at one primary health care center where as other had no record or could not say as shown in table 3.

Forty in-depth interviews were also conducted involving a total of forty respondents. The mean age of the respondents was $34.1 \pm 7.1$. There were 3 males and 37 females with $65 \%$ from Esan tribe and over fifty 
percent had secondary level of education and about forty with tertiary level of education as shown in table 4.

Over $90 \%(37 / 40)$ of the respondents were aware of the burden for maternal death and were concerned because of its far reaching consequences. Major causes of maternal death identified were haemorrhage, hypertension/convulsion in pregnancy and prolong labour. When asked why mother still die in pregnancy and child birth, over $70 \%$ said poor antenatal care, lack of money, inappropriate referral network, delay in receiving treatment in the hospital, attitude of health care providers, lack of necessary equipments. One midwife in one of the health centers said lack of fund and having a free alternative care make patient with serious complication to reject referral to tertiary health care and go to free missionary maternity homes. Another said even after adequate counseling this patient will decline referral to tertiary care. "Saying just do what you can nurse but to go there no". "They don't care; there is undue delay to treatment, turning them here and there as errant boys". Another midwife shared her experience that she will even prefer to refer them to private hospitals other than the tertiary hospital because of the attitude of fellow doctors and nurses laying blames on her care before referring patient. That in one of the occasions she followed the patient down in a hired cab only for the relative to be told by the health care provider that she causes the damage"

Suggested solutions to these problems includes supply of necessary drugs and equipments, training and re-training of skilled birth attendant, community and health care providers reorientation. Overall response of participant about the quality of emergency obstetric care services in the area was low 26(65\%), $13(32.5 \%)$ very low, 1(2.5\%) high and none replied very high as showed in figure 2.

\section{Discussion}

This study was design to evaluate the availability and quality of emergency obstetric and newborn care EmONC services in Esan Central LGA of Edo State. There is limited availability of EmONC services at the primary and secondary level of care. The availability of EmONC services is 3.7/500000 population, this is less than the UN recommendation of 5/ 500000 population. There are seventeen registered primary health care centres that should be able to carry out basic EmONC services with two district hospitals design as secondary health care centre but none could offer all the seven versus nine EmOC signal functions respectively. However the comprehensive EmOC services are available at the tertiary health care facility. This is $3.7 / 500000$ population, which is adequate as recommended by the UN of at least one comprehensive EmOC centre for 500000 populations. This finding is not different from other studies showing adequacy of comprehensive EmOC services with limited basic EmONC services [4-6, 11, 21, 26, $27-30,32-51,54-57]$. Paxton et al in a survey of global patterns in availability of EmOC found that comprehensive EmOC are usually available to meet the recommended minimum number for the size of the population; however basic EmOC facilities are consistently not available in sufficient numbers [6]. The major identified causes of maternal mortality are haemorrhage, hypertension/ convulsion and prolong labour. Universally there are available oxytocics and antibiotics but magnesium sulphate is not available. One midwife when interviewed on how she manage cases of high blood pressure said she gives anti- 
hypertensive drugs and if patient fails to response she will refer, another said she will just refer. Eclampsia contributes majorly to maternal mortality; however it can be prevented and treated with early administration of magnesium sulphate to women with severe pre eclampsia but not available universally at the primary and secondary levels.

The overall rating for quality of EmOC in the area is poor. The met need for EmOC was $62.5 \%$. This is below the $100 \%$ recommended by the UN. And the obstetric case fatality was $1.2 \%$ and is higher than the UN recommendation of less than $1 \%$. This suggests higher maternal death. One of the tools to reducing maternal mortality is access to quality EmONC services $[2,4]$ Its availability is lacking in the area especially at the primary and secondary health care level. At the tertiary health care level there is available comprehensive EmONC services; however many women who would have needed same could not afford them [25]. Not only fund but also there is inappropriate referral due to the attitudes of health care provider, undue delay to treatment and laying of blame to primary health care providers. Abdou et al in 2011 report cost of care as one of the major contributing factors to poor access to EmOC services [59]. There is a similar report by Essendi et al [60]. Many of these women who would have needed EmOC services decline referral to tertiary health care center and opt for missionary maternity home only to represent at these facility when their condition had deteriorate badly contributing to delay $[12,25,39]$. Maternal mortality in the area was high at estimate of $1747 / 100000$ live births by Okunsanya et al in 2007 . Their major finding was that $77.8 \%$ of these maternal death results from delays [12]. Omo-Aghoja et al in Benin also noted that the high maternal mortality was largely due to delay mainly from delayed referral [25]. But why the delayed presentation was questioned [25]. This study shows that these delays are largely due to inappropriate referral, lack of money to access tertiary care and attitudes of the health care providers. This was reported by majority of the respondents in the in-depth interviews. In PHC when these patient presents with life threatening complication beyond the PHC services and needed prompt referral to a tertiary care. They will decline saying 'nurse please just do what you can do' but to go there no'.

The population based estimate of caesarean section rate was $24 \%$, this is higher than the UN recommendation of 5-15\%. It may suggest access to life saving skills but also may suggest a pointer to delay in patient presentation with life threatening condition to either the mother or the baby. This caesarean section was only available at the tertiary level but not in the secondary level.

Availability of skill birth attendant is necessary of quality EmONC services. There are nurses and midwife available at the PHC centers and secondary health care centers but no 24 hours coverage. One doctor is available only on emergency call basis and covers all the centres. It is only at the tertiary level that there are available nurse, midwives, doctors and obstetricians on a functional 24 hour duty roster. This is similar to the findings of Wit et al that there is no SBA available for 24 hour EmOC coverage for basic EmOC services [27]. Obstetric emergencies are no respecter of the time of the day, no wonder the UN recommendation that for a facility to be certified of having available EmOC services. These services must be available for 24 hours a day and seven days a week and for a period of functional services for 3 months. 
As we move toward achieving the sustainable development goals (SDG) especially in reducing maternal mortality to less than 70/ 100000 live birth. There is urgent need to rehabilitate the primary and secondary health care facilities through equipment and drug supply and training and re training of more skill birth attendants. This was suggested by the participant as these facilities are very close to the people and in agreement with the national agenda of health for all through the primary health care. Also reorientation of the community and health care staff on the client oriented care needs of patient, good referral and communication network between the levels of health care [24,25].

\section{Conclusion}

There are limited EmOC services at the primary and secondary health centers that require urgent attention in effort to reducing maternal mortality. There is need for supply of equipment, emergency obstetric care drugs, training and re-training of staff. The community and the health care providers need re-orientation as to the reproductive health care needs in a manner that is client centered and appropriate prompt referral network.

\section{RECOMMENDATIONS}

There is urgent need for the government, community to team up to upgrade all the primary and secondary health center in the area

The health care workers to have a town hall meeting for community education and awareness of the available of these services at the tertiary hospital in a manner that meet their need and at an affordable cost.

There should be a good referral and communication network between the levels of health care most especially as regard obstetric emergencies.

\section{Abbreviations}

AMDD - Averting Maternal Death and Disability

AVD- Assisted vaginal delivery

B-EmOC - Basic Emergency Obstetric Care

BNR-Basic neonatal resuscitation

C-EmOC - Comprehensive Emergency Obstetric Care

C/S - Caesarean section

EmOC - Emergency Obstetric Care 
EOC - Emergency obstetric care

EmONC - Emergency Obstetric and Newborn Care

FMOH - Federal Ministry of Health

IDI - In-depth Interview

ISTH - Irrua Specialist Teaching Hospital

MDG - Millennium Development Goals

MMR - Maternal Mortality Ratio

MVA - Manual Vacuum Aspirator

NDHS - National Demography and Health Survey

PHC - Primary Health Care

RPOC- Retained product of conception

SBA - Skilled Birth Attendant

SBT-Safe blood transfusion

SDG - Sustainable Development Goals

SPSS - Statistical Package for Social Sciences

UN - United Nation

UNICEF - United Nations International Children's Emergency Fund

WHO - World Health Organization

\section{Declarations}

ETHICS APPROVAL AND CONSENT TO PARTICIPATE. Ethical approval was obtained from the ethical committee of Irrua Specialist Teaching Hospital, Irrua (ISTH / HREC / 20171219/47).

Consent was obtained from participant for the IDI.

COMPETING INTERESTS

We declare no conflict of interest and no funding for this work. 
We are grateful to the Primary Health Care coordinator for his assistance and also Engr. White for audiotape coverage during the interview.

AUTHOR'S CONTRIBUTIONS. The study was carried out in collaboration of fur authors. The corresponding author JS and the second author EE co-designed the study, developed the protocol, literature review, data analysis and interpretation. Author NA and AJ in addition to JS conducted also the data analysis, interpretation and drafted the manuscript and proof read it. All authors read and approved the final report.

AVAILABILITY OF DATA AND MATERIALS. The datasets generated and/or analysed during the current study are not publicly available due to the fact that I did not have permission to do so, but are available from the corresponding author on reasonable request.

\section{References}

1. Trends in maternal mortality: 1990 to 2015: estimates by WHO, UNICEF, UNFPA, World Bank Group and the United Nations Population Division. Geneva: World Health Organization; 2015.

2. Paxton A, Maine D, Freedman L, Fry D, Lobis S. The evidence for Emergency Obstetric care. International Journal of Gynaecology obstetrics 2005; 88: 181-193.

3. Oladapo OT, Adetoro OO, Ekele BA, et al. When getting there is not enough: a nationwide crosssectional study of 998 maternal deaths and 1451 near-misses in public tertiary hospitals in a lowincome country. BJOG 2015; DOI: 10.111

4. Ameh C, Adegoke A, Kongnyuy E, Dornan J, et al. Improving essential obstetric and newborn care in resource-poor countries. J Obstet Gynaec. 2011: 31; 18-23.

5. Babatunde S, Mezie-okoye MM, Adeniji FO, Tobin-west Cl. Status of Emergency obstetric care in a local government area in south- south Nigeria. African Journal of Reproductive Health. 2012; 16(3):170-179.

6. Paxton A, bailey P, Lobis S, Fry D. Global pattern in availability of emergency obstetric care. Int. J Gynaecology Obstet. 2006; 93(3): 300-7.

7. Miller S, Abalos E, Chamard M, Ciapponi A et al. Beyound too little, too late or too much soon: a pathway towards evidenced based respectful maternity care worldwide. The lancet maternal health series papper 2.

8. Erim DO, Kolapo NM, Reschse A, Rapid assessment of the availability and use of Obstetric care in Nigerian health care facilities 2012. Plos- one 7(6) e 39553

9. National Population Commission- NPC/Nigeria and ICF international.2014. Nigerian Demographic and Health Survey, 2013. Abuja: Nigeria NPC/ ICF- International (NDHS 2013).

10. United Nations. Sustainable development goals: 17 goals to transform our world. Sustain.Dev.2015.Availablefrom:http://www.un.org/sustainabledevelopment/sustainable- 
development-goals/ [assassed 9 January 2016].

11. Ameh C, Msuya S, Hofman J, Raven J, Mathai M, et al. Status of Emergency Obstetric Care in Six Developing Countries Five Years before the MDG Targets for Maternal and Newborn Health. PLoS ONE. 2012 (7) (12): e49938. doi:10.1371/journal.pone.0049938

12. Okunsanya BA, Okogbo FO, Momoh M, Abebe JO. Maternal mortality and Delay: sociodemographic characteristics of maternal deaths with delay in Irrua, Nigeria. Nigerian journal of medicine. 2007,16(1):38-40.

13. Rana TG, Chataut BD, Shakya G, Nanda G, Pratt A, Sakai S. Strengthening emergency obstetric care in Napa: The women's right to life and health project(WRLHP). Int J Gynaecol obstet. 2007 vol 98 issue 3.

14. Priyamadhaba Behra, Kiran Goswami. Reducing maternal deaths in India: will good emergency obstetrics care be useful? The national medical journal of india. 2014;27(1)

15. Fawole AO, Oladapo O, Fabamwo AO, El-Laden A, Almustapha M, Okunsanya B, Abe A et al. Quality Obstetrics care in Nigeria: Lessons from the WHO Multi-country survey on Maternal Near- Miss. Trop J Obstet Gynaecol 2013; 30(suppl.) S46-47.

16. World health Organization. Beyond the numbers: reviewing maternal deaths and complication to make pregnancy safer. Geneva. 2004. WHO.

17. Dumont A, Fournier P, Abrahamowicz M, Traore M, Haddad S, Fraser WD. Quality of care, risk management and technology in obstetrics to reduce hospital-based maternal mortality in Senegal and Mali(QUARITE): A cluster-randomized trial. Lancet 2013; 384:146-57.

18. WHO, UNFPA, UNICEF, AMDD (2009). Monitoring emergency obstetric care: a handbook. Geneva, Switzerland: WHO Press.

19. Averting Maternal Deaths and Disability. AMDD needs assessment toolkit. New York: Averting Maternal Deaths and Disability. 2009.

20. Holmer H, Oyerinde K, Meara JG, Gillies R, Liljestrand J, Hagander L. The global met need for EmOC; A systematic review. BJOG 2015: 122;183-189.

21. Bangoura, I. F., Hu, J., Gong, X. et al. Availability and quality of emergency obstetric care, an alternative strategy to reduce maternal mortality: Experience of Tongji Hospital, Wuhan, China J. Huazhong Univ. Sci. Technol. [Med. Sci.] 2012; 32: 151. doi: 10.1007/s11596-012-0028-4.

22. Federal Ministry of Health (NIG.). National study on Essential Obstetrics care in Nigeria, Abuja. Federal Ministry of Health. 2003.

23. Wilunda C, Koyejo O, Giovanni P, Lochoro P et al. Availability, utilization and quality of maternal and neonatal health care services in Karamoja region, Uganda: a health facility-based survey.Reproductive health 2015;12.30

24. Pearson L, Shoo R. Availability and use of emergency obstetric services: Kenya, Rwanda, Southern Sudan and Uganda. International journal of Gynaecology and Obstetrics, 2005; 88:208-215. 
25. L. O. Omo-Aghoja, O. A. Aisien, J. T. Akuse, S. Bergstrom and F. E. Okonofua Maternal mortality and emergency obstetric care in Benin City, South-south Nigeria. Journal of Clinical Medicine and Research. April 2010; Vol. 2(4), pp.055-060,

26. Rahma Muhammad Bakari, Damian Jeremia Damian, Patricia Swai, Ahmad Mohamed Makuwani, Michael Johnson Mahande, SiaEmmanueli Msuya. Assessment of Availability, Utilization and Quality of Emergency Obstetric Care in 2014 at Hai District, Northern, Tanzania. Journal of Gynecology and Obstetrics. Vol. 3, No. 3, 2015, pp. 43-48. doi: 10.11648/j.jgo.20150303.11

27. Wit Wichaidit, Mahbub-UIAlam, Amalk Halder, Pavanik Ram.. Availability and quality of emergency Obstetrics and newborn care in Bangladesh. Am J Trop Med Hyg.2016; 95:298-306.

28. Say L, Chou D, Gemmill A, Tunçalp Ö, Moller A-B, Daniels J, et al. Global causes of maternal death: a WHO systematic analysis. Lancet Glob Health 2014; 2: e323-33.

29. Oyerinde K. Emergency obstetric and newborn care assessments in Africa: focus on post partum hemorrhage \& pre-eclampsia/eclampsia. Africa Reg Meet Matern Newborn Heal Interv 2011, OI/MCHIP Meet Addis Ababa, Ethiopia, 21-25 February 2011.

30. Admasu K, Haile-Mariam A, Bailey P. Indicators for availability, utilization, and quality of emergency obstetric care in Ethiopia 2008. Int J Gynaecol Obstet 2011; 115: 101-5.

31. Alam B, Mridha MK, B iswas TK, Roy L, Rahman M, Chowdhury ME. Coverage of emergency obstetric care and availability of services in public and private health facilities in Bangladesh. Int $\mathrm{J}$ Gynaecol Obstet 2015; 131: 63-9.

32. Ameh C, Msuya S, Hofman J, Raven J, Mathai M, van den Broek N. Status of emergency obstetric care in six developing countries five years before the MDG targets for maternal and newborn health. PLoS ONE 2012; 7: e49938.

33. Bosomprah S, Tatem AJ, Dotse-Gborgbortsi W, Aboagye P, Matthews Z. Spatial distribution of emergency obstetric and newborn care services in Ghana: using the evidence to plan interventions. Int J Gynaecol Obstet 2016; 132: 130-4.

34. Douangphachanh X, Ali M, Outavong P, Alongkon P, Sing M, Chushi K. Availability and use of emergency obstetric care services in public hospitals in Laos PDR: a systems analysis. Biosci Trends 2010; 4: 318-24.

35. Echoka E, Kombe Y, Dubourg D, Makokha A, Evjen-Olsen B, Mwangi M, et al. Existence and functionality of emergency obstetric care services at district level in Kenya: theoretical coverage versus reality. BMC Health Serv Res 2013; 13.

36. Fakih B, Nofly AAS, Ali AO, Mkopi A, Hassan A, Ali AM, et al. The status of maternal and newborn health care services in Zanzibar. BMC Pregnancy Childbirth 2016; 16: 134.

37. Gabrysch S, Simushi V, Campbell OMR. Availability and distribution of, and geographic access to emergency obstetric care in Zambia. Int J Gynaecol Obstet 2011; 114: 174-9.

38. Hanson C, Ronsmans C, Penfold S, Maokola W, Manzi F, Jaribu J, et al. Health system support for childbirth care in Southern Tanzania: results from a health facility census. BMC Res Notes 2013; 6: 435 . 
39. Hirose A, Borchert M, Cox J, Alkozai AS, Filippi V. Determinants of delays in travelling to an emergency obstetric care facility in Herat, Afghanistan: an analysis of cross-sectional survey data and spatial modelling. BMC Pregnancy Childbirth 2015; 15: 14.

40. Kim Y-M, Zainullah P, Mungia J, Tappis H, Bartlett L, Zaka N. Availability and quality of emergency obstetric and neonatal care services in Afghanistan. Int J Gynaecol Obstet 2012; 116: 192-6.

41. Kongnyuy EJ, Hofman J, Mlava G, Mhango C, van den Broek N. Availability, utilisation and quality of basic and comprehensive emergency obstetric care services in Malawi. Matern Child Health J 2009; 13: $687-94$

42. Owens L, Semrau K, Mbewe R, Musokotwane K, Grogan C, Maine D, et al. The state of routine and emergency obstetric and neonatal care in Southern Province, Zambia. Int J Gynaecol Obstet 2015; 128: $53-7$.

43. Saidu R, August EM, Alio AP, Salihu HM, Saka MJ, Jimoh AAG. An assessment of essential maternal health services in Kwara State, Nigeria. Afr J Reprod Health 2013; 17: 41-8.

44. Wilunda C, Oyerinde K, Putoto G, Lochoro P, Dall'Oglio G, Manenti F, et al. Availability, utilisation and quality of maternal and neonatal health care services in Karamoja region, Uganda: a health facilitybased survey. Reprod Health 2015; 12: 30.

45. Ali M, Ahmed KM, Kuroiwa C. Emergency obstetric care in Punjab, Pakistan: improvement needed. Eur J Contracept Reprod Health Care 2008; 13: 201-7.

46. Anwar I, Kalim N, Koblinsky M. Quality of obstetric care in public-sector facilities and constraints to implementing emergency obstetric care services: evidence from high- and low-performing districts of Bangladesh. J Health Popul Nutr 2009; 27: 139-55.

47. Nesbitt RC, Lohela TJ, Manu A, Vesel L, Okyere E, Edmond K, et al. Quality along the continuum: a health facility assessment of intrapartum and postnatal care in Ghana. PLoS One 2013; 8: e81089

48. Aduragbemi Banke-Thomas, Kikelomo Wright, Olatunji Sonoiki,Oluwasola Banke-Thomas, Babatunde Ajayi, Onaedo llozumba, and Oluwarotimi Akinola. Assessing emergency obstetric care provision in low- and middle-income countries: a systematic review of the application of global guidelines. GlobHealth Action. 2016; 9: 10.3402/gha.v9.31880.

49. Utz B, Zafar S, Arshad N, Kana T, Gopalakrishnan S. Status of emergency obstetric care in four districts of Punjab, Pakistan-results of a baseline assessment. J Pak Med Assoc 2015; 65: 480-5.

50. Ameh CA, Bishop S, Kongnyuy E, Grady K, Van den Broek N. Challenges to the provision of emergency obstetric care in Iraq. Matern Child Health J 2009; 15: 4-11.

51. Rigoli F, dussault G. The interface between health sector reform and human resources in health. HR for health, 2003.1.9.

52. Essendi $\mathrm{H}$ et al. infrastructural challenges to better health in maternity facilities in rural Kenya: Community and heath workers perceptions. Reproductive Health, 2015.12.103.

53. Rikiku F. Factors that can affect the quality of EmOC in health centre level in developing countries: $A$ systematic review of literature. Pyrex Journal of nursing and midwifery Aug, 2016; vol 2(2) pp 7-11. 
54. Duysburgh E, Zhang W-H, Ye M, Williams A, Massawe S, Sié A, et al. Quality of antenatal and childbirth care in selected rural health facilities in Burkina Faso, Ghana and Tanzania: similar finding. Trop Med Int Health 2013; 18: 534-47.

55. Pattinson RC, Makin JD, Pillay Y, van der Broek N, Moodley J. Basic and comprehensive emergency obstetric and neonatal care in 12 South African health districts. S Afr Med J 2015; 105: 256-60.

56. Ueno E, Adegoke AA, Masenga G, Fimbo J, Msuya SE. Skilled birth attendants in Tanzania: a descriptive study of cadres and emergency obstetric care signal functions performed. Matern Child Health J 2015; 19: 155-69.

57. Oyerinde K, Harding Y, Amara P, Kanu R, Shoo R et al. The status of maternal and newborn care services in Sierra Leone 8 years after ceasefire. International Journal of Gynaecology and Obstetrics 2011, 114(2): 168-73.

58. Olenja,Joyce, Pamela Godia, Josephine Kibaru, and Thaddaeus Egondi.2009. Influence of Provider Training on Quality of Emergency Obstetric Care in Kenya. Kenya Working Papers No.3. Calverton, Maryland, USA: Macro International Inc.

59. Abdou J, Johanne S and Siri V. Barriers to emergency obstetrics care servicescin perinatal deaths in rural Gambia: A qualitative In-Depth interview study. Obstetrics and Gynaecology.2011, Vol.11.

60. Essendi H, Samuel H, Jean-Christophe J. Barriers to formal EmOC service utilization.J. Urban Health, 2011, Jun 88(Supp -2); 356-369.

\section{Tables}

TABLE. 1 LEVEL OF HEALTH FACILITY AND TYPES

\begin{tabular}{|lll|}
\hline LEVEL & & FREQUENCY/PERCENTAGE \\
\hline & PRIMARY & $17(85)$ \\
\hline & SECONDARY & $2(10)$ \\
\hline & TERTIARY & $1(5)$ \\
\hline TYPE & & \\
\hline & PUBLIC & $17(85)$ \\
\hline & PRIVATE & $5(15)$ \\
\hline
\end{tabular}

\section{Due to technical limitations, Table 2 is only available as a download in the supplemental files section.}


TABLE 3. LEVEL OF HEALTH CARE, SBA, 24 HOUR COVERAGE AND MATERNAL DEATH RECORD

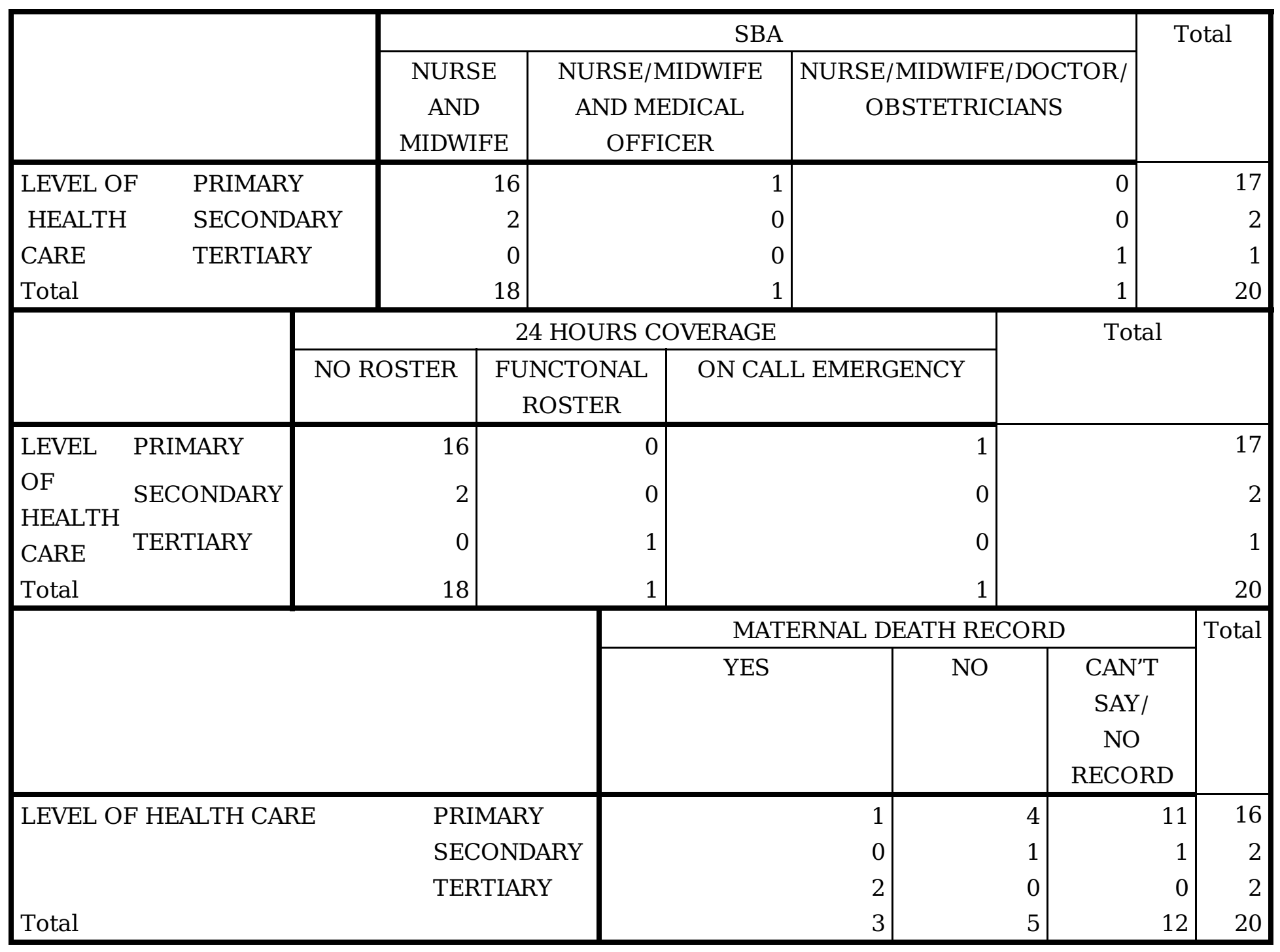

TABLE 4. SOCIO-DEMOGRAPHIC CHARACTERISTICS OF RESPONDENTS

Variable

Mean age

Sex

Female

Male
Number/ Percentages

$34.1 \pm 7.1$
$37(92.5$

3 (7.5)

Tribe 
Esan

Owan

Benin

Etsako

Ibo

Yoruba
$26(65.0)$

$4(10.0)$

$2(5.0)$

$6(15.0)$

$1(2.5)$

$1(2.5)$

Level of Education

No formal education

Primary

Secondary

Tertiary
$1(2.5)$

$1(2.5)$

$21(52.5)$

$17(42.5)$

Figures

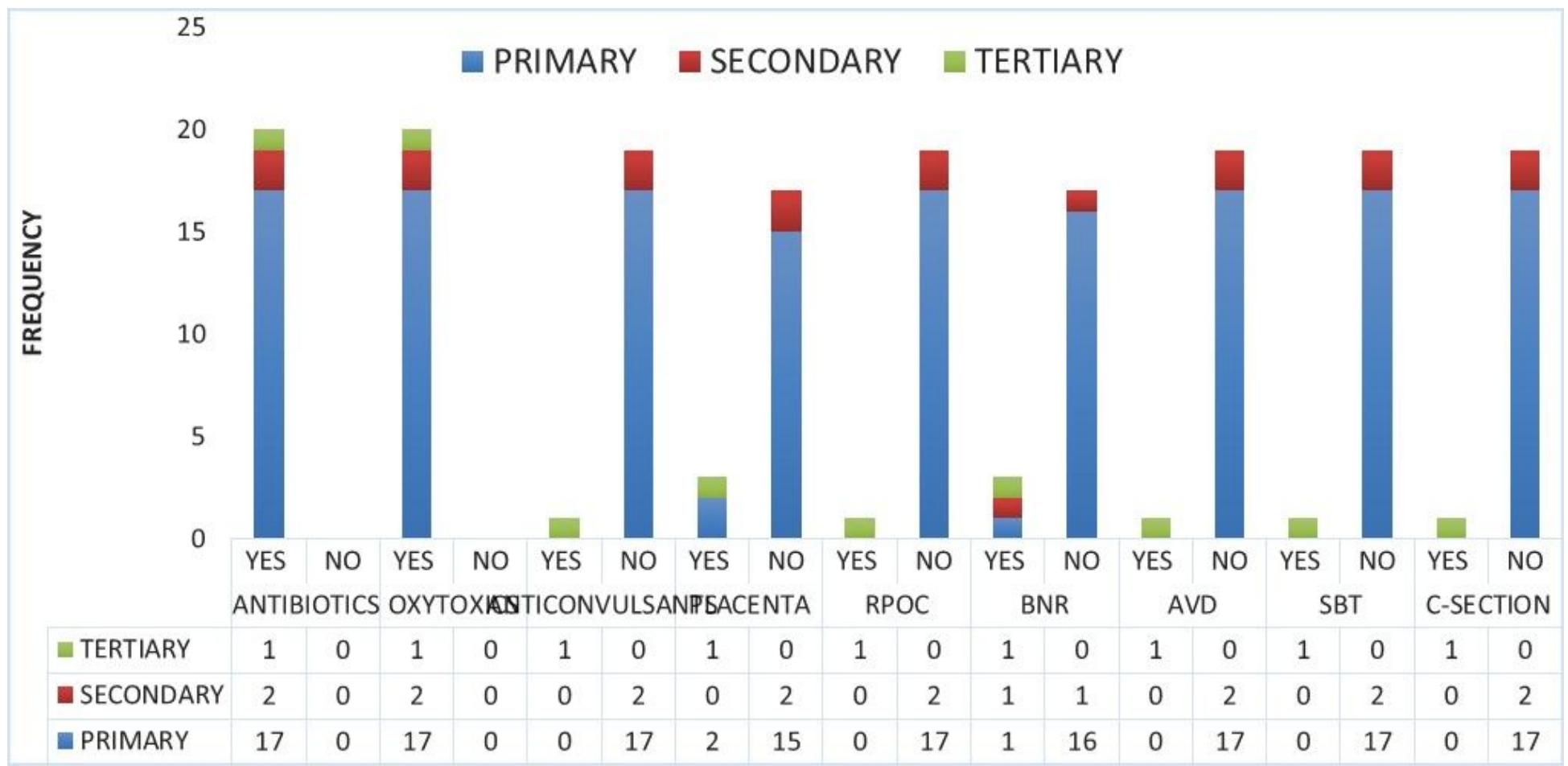

Figure 1 
Bar chart showing the availability of EmONC signal functions at the three levels of health care

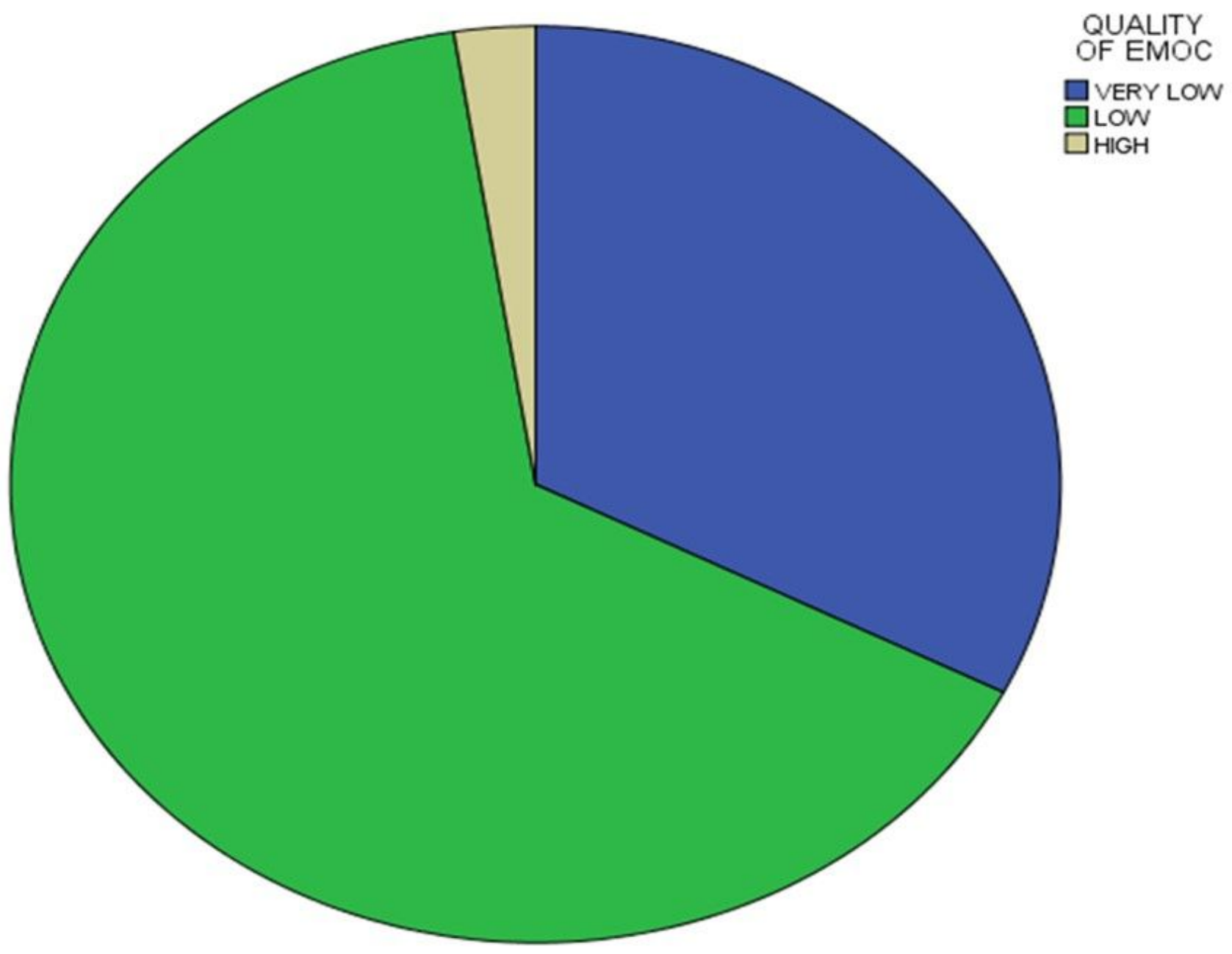

Figure 2

Participant perception of the quality of EmOC services in ESAN central LGA

\section{Supplementary Files}

This is a list of supplementary files associated with this preprint. Click to download.

- Table2.jpg

- STROBEchecklistemocpaper.docx 